\title{
Prenatal development as a predisposing factor for perinatal losses in pigs
}

\author{
T. van der Lende ${ }^{1}$, E. F. Knol ${ }^{2}$ and J. I. Leenhouwers ${ }^{1}$ \\ 'Animal Breeding and Genetics Group, Wageningen Institute of Animal Sciences (WIAS), \\ Wageningen University, PO Box 338, 6700 AH Wageningen, The Netherlands; and 'Institute \\ for Pig Genetics, PO Box 43, 6640 AA Beuningen, The Netherlands
}

\begin{abstract}
The pig industry is confronted with substantial losses due to piglet mortality. With 3-8\% stillbirths and generally $>10 \%$ preweaning mortality, approximately one fifth of all fetuses formed fully at the end of gestation die before weaning. Most of these losses occur in the perinatal period. Overall prenatal development (birth weight) and specific prenatal developmental and maturational processes in late gestation are predisposing factors for perinatal losses. Birth weight and variation in birth weight remain important risk factors for perinatal mortality. Genetic selection against piglet mortality will not necessarily increase birth weight but will affect body composition and proportional organ development. Many maturational processes that occur in late gestation in preparation for extrauterine life, for example specific biochemical changes in the gastrointestinal tract, are influenced by glucocorticosteroids and are, therefore, dependent on maturation of the pituitary-adrenal system. The carbohydrate metabolism of perinatal piglets is related closely to viability in the perinatal period. The prenatal deposition of carbohydrate reserves (glycogen) and prenatal effects on perinatal glucogenic capacity, glucose homeostasis, carbohydrate metabolism and thermostability are reviewed.
\end{abstract}

\section{Introduction}

The pig industry is confronted with substantial losses due to piglet mortality. Approximately one fifth of all fetuses formed fully at the end of gestation die before weaning. Most of these economically important losses occur during the perinatal period, which is the period from the onset of parturition to 2-3 days after completion of parturition. The ability of a piglet to withstand the stresses associated with birth and its competence to adapt to the postnatal environment are crucial to survive this period. Stillbirths and piglets with a low viability at birth reflect both suboptimal prenatal development and pathology associated with parturition. In this review, predisposing factors for perinatal losses that are related to impaired prenatal development and, more generally, to intra- and inter-litter variation in prenatal development, will be discussed. As many of the physiological and biochemical changes in preparation for birth occur during the period of rapid fetal growth in the second half of gestation, emphasis will be on this period. Genetic abnormalities in prenatal development leading to congenital anomalies at birth are relatively unimportant as a cause of perinatal piglet mortality and, therefore, will not be discussed in this review. 


\section{Perinatal losses}

\section{Stillbirth}

On average, $3-8 \%$ of all near-term fully grown fetuses are stillborn. Many sow factors influence the number of stillbirths per litter or the probability of stillbirth, including parity, condition of the sow, duration of gestation, total number of piglets in the litter and average birth weight of the litter. Post-mortem examinations indicate that approximately $10 \%$ of stillborn piglets died shortly before parturition (late prepartum deaths), approximately $75 \%$ died during parturition (intra-partum deaths) and approximately $15 \%$ died immediately after expulsion (immediate postpartum deaths) (Clastonbury, 1977; English and Morrison, 1984; J. I. Leenhouwers, unpublished). Piglets in the immediate postpartum category can be identified by the presence of air in their lungs and, strictly speaking, are not stillborn, but in practice are generally recorded as stillbirths.

Very little is known about the causes of prepartum deaths. In a study including 336 purebred litters, prepartum stillborn piglets were heavier on average than non-fresh stillborn, intra-partum stillborn and postpartum stillborn piglets (J. I. Leenhouwers, unpublished). Furthermore, prepartum stillborn piglets were heavier than live-born piglets that died within a day of birth, but were not different in weight from live-born piglets that survived the first day after birth. Although more data are needed to substantiate this observation, this study indicates that late prepartum death is not associated with retarded development but rather with precocious maturation. It is generally accepted that intra-partum and immediate postpartum deaths are predominantly a result of fetal asphyxiation (Sprecher et al., 1974; Stanton and Carroll, 1974). Piglets that were exposed to $95 \% \mathrm{~N}_{2}: 5 \% \mathrm{CO}_{2}$ immediately after birth survived $<5 \mathrm{~min}$ (Miller and Miller, 1965). Therefore, it can be concluded that, on average, intrapartum stillborn piglets experienced only a relatively short period of anoxia or a somewhat longer period of severe hypoxia. During normal delivery, fetal homeostasis is maintained, even in piglets delivered late in the farrowing order, providing that the umbilical circulation and placental exchange area are not compromised (Randall, 1982). Although cervicotubally directed myometrial contractions occur during farrowing to avoid untimely interruption of the fetal-placental-maternal connections (Taverne et al., 1979), these contractions are obviously not fully effective, as most stillborn piglets occur in the second half of farrowing, often with broken umbilical cords (Randall, 1972a,b). The length of the umbilical cord correlates with the length and birth weight of the piglet, but not with piglet position in the uterus (Randall, 1989a). Zaleski and Hacker (1993) determined variables related to the progress of parturition and the probability of stillbirth, and found that the effect of a broken umbilical cord was additional to the effect of position in the birth order. These authors concluded that the effect of a later position in the birth order on the probability of stillbirth could not be explained only by the increased danger of breaking the cord as distance travelled through the uterus increased.

\section{Early preweaning mortality}

Owing to large herd to herd variation in environmental conditions, farrowing systems and management (for example, supervision during the perinatal period), the percentage of liveborn piglets that die before weaning may show considerable variation, ranging from $5 \%$ to $30 \%$. In most western countries, where labour is expensive and, therefore, the level of supervision at farrowing is generally low, preweaning mortality rates are often $>10 \%$. Approximately $50 \%$ or more of all preweaning mortality occurs within 3-4 days after birth, during the period in which the piglet has to recover from the stress of birth and has to adapt to its new environment. In addition, it is generally accepted that a substantial part of the 
preweaning mortality after the first 3 days of life also results from problems of adaptation and development.

Undersized piglets and piglets with a low viability at birth have a higher probability of dying as a result of trauma, chilling or starvation than do their larger or more viable littermates (English and Smith, 1975; van der Lende and De Jager, 1991). Among the piglets with a low viability at birth are the piglets that suffered anoxia or severe hypoxia during parturition (Sprecher et al., 1974). Although these piglets survive parturition, they may be lethargic or disoriented (Stanton and Carroll, 1974; Svendsen, 1992). They have a reduced ability to adapt to extrauterine life (Herpin et al., 1996) and to compete with their littermates for colostrum at a critical period of life. The degree of anoxia in live-born piglets can be measured by blood lactate concentration (Dawes et al., 1963). English and Smith (1975) found that live-born piglets dying before week 3 of age had a significantly higher average lactate concentration directly after birth than did those surviving at least 3 weeks ( 383.3 versus $303.0 \mu \mathrm{g}$ lactate $\mathrm{ml}^{-1}$ blood, respectively; $P<0.01$ ). According to more recent work by Herpin et al. (1999), the lower viability of piglets suffering from asphyxia during delivery is not due to impaired thermoregulatory ability after birth, but may be a consequence of reduced vigour and colostrum intake, and short term alterations in carbohydrate metabolism. As far as reduced vigour is concerned, many pathophysiological consequences of parturient hypoxia have been described, including circulatory, metabolic and neurological disturbances. Effects of parturient hypoxia on the central nervous system may include brain damage. Evidence for cellular injury in the hypoxic brain of perinatal piglets is provided, for example, from the expression of the heat shock protein gene hsp72 (Murphy et al., 1996), and DNA fragmentation in different regions of the brain such as the cerebellum, cortex, hippocampus and striatum (David and Grongnet, 2000). The hypoxia-induced metabolic acidosis can cause defects in the brain microvascular endothelial cells, leading to breakdown of the blood-brain barrier (Hsu et al., 1996).

The viability of piglets that suffer anoxia or hypoxia during parturition may also be affected by the secretion of $\beta$-endorphin into the fetoplacental circulation in response to the stress of delivery. Chiang and Rodway (1997) found a significant positive correlation between umbilical cord plasma $\mathrm{pCO}_{2}$ and $\beta$-endorphin concentration. The correlation between umbilical cord plasma $\mathrm{pH}$ and $\beta$-endorphin concentration was significantly negative. $\beta$ endorphin is known to induce cardiorespiratory depression (Moss and Scarpelli, 1981). Therefore, the neonatal cardiorespiratory control may be affected in asphyxiated piglets, especially if the $\beta$-endorphin concentrations remain high or even increase for some time after birth.

\section{Prenatal development in relation to perinatal mortality}

\section{Prenatal growth and birth weight}

A large variation between and within litters in overall prenatal development is evident from the substantial variation in birth weight. Birth weight is an important risk factor for perinatal mortality in all breeds studied (for example see Leenhouwers et al., 1999; Roehe and Kalm, 2000; Tuchscherer et al., 2000). Therefore, it is evident that prenatal development is a predisposing factor for perinatal mortality. Birth weight is influenced by sow genotype rather than piglet genotype (Lee and Haley, 1995; Roehe, 1999). An important maternal trait in this respect is uterine capacity. At a given litter size, the fetuses in sows with larger uterine capacities will have an advantage in terms of placental development (mass, vascularity and surface area) compared with fetuses in sows with more limiting uterine capacities. Next to birth weight per se, within-litter variation in birth weight is also an important risk factor for 
piglet mortality (English and Smith, 1975). Within-litter variation in birth weight is largely a result of variation in placental mass (Waldorf et al., 1975; Wise et al., 1997; B. T. T. M. Van Rens, unpublished).

Various studies have shown that pig fetuses with a low weight at onset of farrowing have an increased likelihood of intra-partum death compared with heavier littermates (Björklund et al., 1987; J. I. Leenhouwers, unpublished). On the basis of low body weight of many piglets that died intra-partum and the higher incidence of specific irregularities in the liver, kidneys and thyroid in such piglets, Björklund et al. (1987) suggested that at least some intra-partum deaths are related to disturbance in the fetal growth pattern. According to these authors, this contention supports the earlier suggestion of Svendsen (1982) that fetal asphyxiation during farrowing may be "...superimposed upon a prior disease or abnormality of the affected individuals, rendering them incapable of making a successful transition to extrauterine life...".

Birth weight as a risk factor for preweaning mortality is often related to the inability of low birthweight piglets to compete with littermates for colostrum, especially in litters with a large within-litter variation in birth weight (for review see Fraser et al., 1995). In addition, there is evidence that there are developmental differences between low birthweight piglets and their heavier littermates that influence the likelihood of survival after birth. For example, Thornbury et al. (1993) found spontaneous necrotizing enterocolitis-like pathological lesions in low birthweight piglets (529-1510 g) of Large White $\times$ Landrace crossbred litters, but did not find such lesions in their littermates with average birth weights (1815-2140 g). The lesions were observed mainly in the distal ileum, with mucosal and submucosal necrosis, indicative of ischaemic injury. From a difference in the extent and severity of pathology between the gut and other organs, it was concluded that the processes finally leading to neonatal necrotizing enterocolitis-like lesions in low birthweight piglets had already started in utero. A second example comes from the work of Wise et al. (1997). These workers found lower cholesterol concentrations in day 104 lightweight fetuses in a white composite breed than in mean weight or heavyweight fetuses. From these studies it was concluded that the high mortality in lightweight piglets might be due not only to inadequate physical maturation and substandard nutrition, but also to inadequate development of the central nervous system. The possibility that inadequate development of the central nervous system might have a role was concluded from the fact that neonatal piglets from pig lines with genetically low cholesterol contents appear to be lethargic at birth and show reduced exploratory behaviour (Schoknecht et al., 1994; Pond and Mersmann, 1995). The exploratory behaviour of low cholesterol piglets can be improved by feeding them additional cholesterol. Although these examples indicate that the developmental differences between low birthweight piglets and their littermates are negative in terms of survival, this is not always the case. The intestinal transmission of immunoglobulins in newborn piglets is of utmost importance for resistance against pathogens during the suckling period and even after weaning. In contrast to what might be expected, Svendsen et al. (1990) found that the ability of the small intestine of newborn piglets to transmit macromolecules into lymph and blood is negatively related to birth weight and, to a lesser extent, maturity. Small and immature piglets will generally ingest smaller quantities of colostrum as a result of competition with larger littermates, but probably also due to lower sucking vigour when they do successfully obtain a teat. Their greater ability to transmit macromolecules will compensate at least partially for the negative effect of lower ingestion of colostrum on acquired immunity.

Knowing the importance of birth weight as a risk factor for perinatal and preweaning mortality, strategies to increase birth weight by increasing food intake of sows during gestation or by genetic selection have been investigated and suggested, respectively. Attempts to increase birth weight of piglets by increasing food intake of sows in late gestation have had 
limited success (Hillyer and Phillips, 1980; Pond et al., 1981; Sterling and Cline, 1986; Miller et al., 2000). As far as the possibilities for genetic selection for birth weight are concerned, geneticists disagree about the correlated effect on piglet survival. Roehe (1999) and Roehe and Kalm (2000) suggested that direct selection for increased individual birth weight could increase piglet vitality. In contrast, Knol (2001) evaluated different selection strategies for improved piglet survival and concluded that selection for increased individual birth weight will not significantly increase piglet survival. Direct selection for piglet survival is possible but will affect body composition rather than birth weight. Effects on birth weight, although small, will probably be negative rather than positive (Knol, 2001). This seems contradictory to the accepted positive relationship between birth weight and piglet survival. However, within genetic lines and within litters this positive relationship may hold true, but between genetic lines, negative relationships between birth weight and piglet survival have been documented (Mersmann et al., 1984; Kerr and Cameron, 1995).

\section{Specific developmental and maturational processes}

Much information is available about specific aspects of prenatal development, such as the development of specific organs (liver: Bielańska-Osuchowska, 1996; small intestine: Sangild et al., 1995; Buddington and Malo, 1996; Sangild et al., 2000; stomach: Sangild et al., 1991), specific endocrine systems (adrenal/corticosteroid status: Kattesh et al., 1997; thyroid/thyroid hormone status: Berthon et al., 1993) and specific body tissues (fat deposits: Martin et al., 1998). However, it is seldom clear how much variation there is within a population in any specific development and whether this variation merely reflects variation in fetal growth or also body weight-independent variation. As a consequence, little is known about the relative importance of weight-dependent and weight-independent variations in specific prenatal developmental patterns or processes as predisposing factors for perinatal mortality. A good example in this respect is our current knowledge about the prenatal development of the gastrointestinal tract. Maturational changes in the gastrointestinal tracts of fetal pigs during the weeks before birth have been studied intensively (for review see Sangild et al., 2000). Changes that are important for the shift from parenteral nutrition before birth to enteral nutrition after birth include the production and activation of various enzymes involved in digestion (for example, prochymosin and pepsinogen A (Sangild, 1995), and intestinal brush-border disaccharidases and peptidases (Sangild et al., 1995)). Despite the information now available, little is known about the early postnatal consequences of the observed between-piglet variation in enzyme activities for the survival and growth of piglets.

The pituitary-adrenal system. The maturation of the pituitary-adrenal axis in late gestation is essential for preparation of the fetus for the transition from intrauterine to extrauterine life. Experiments with corticotrophin-releasing hormone-deficient mice indicate strongly that the major role of glucocorticosteroids is during fetal rather than postnatal life (Muglia et al., 1995). The glucocorticosteroids, cortisol and corticosterone, are important endocrine factors involved in the maturation of thyroid, lung, gastrointestinal tract, liver, kidney, brain and haemopoietic and lymphatic systems (for review see Liggins, 1994). The role of cortisol in the development and maturation of the gastrointestinal tract of fetal pigs has been reviewed by Sangild et al. (2000). The late prepartum increase in circulating fetal cortisol concentrations affects not only the growth and structure of the gastrointestinal tract, but also the concentrations of disaccharidase enzymes, peptidase enzymes and gastrointestinal hormones. Furthermore, it has a positive effect on the absorption of nutrients from colostrum. From studies in various species it is evident that glucocorticosteroids accelerate the morphological, 


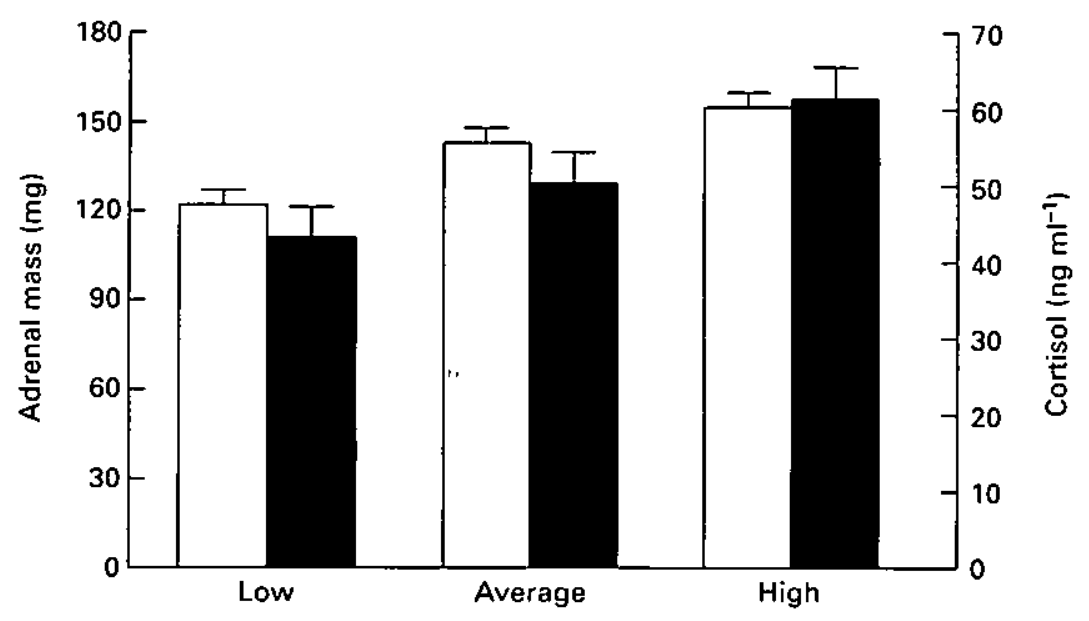

Estimated breeding value for piglet survival

Fig. 1. Adrenal masses $(\square)$ and plasma cortisol concentrations ( $\square$ ) of late gestational pig fetuses with different breeding values for piglet survival. Both adrenal mass and cortisol concentration showed a significant positive linear relationship $(P<0.05)$ with the estimated breeding value for piglet survival (J. I. Leenhouwers, unpublished).

physiological and biochemical maturation of fetal lungs (for reviews see Gross, 1990; Hume et al., 1996). Studies in pigs confirm the important role of cortisol in maturation of the lungs of fetal pigs (Ledwozyw, 1989). From research with rats it is clear that the combined effects of alveolar fluid dilation and glucocorticosteroids might co-ordinate the increased production of lung surfactant as birth approaches (Torday et al., 1998).

Our current knowledge about the development and maturation of the pig hypothalamuspituitary-adrenal axis is limited. The absolute and proportional masses of the adrenal glands in day 112-113 hypophysectomized fetuses were on average significantly lower $(69.5 \mathrm{mg}$ and $5.9 \mathrm{mg}$ (100 g body weight) ${ }^{-1}$, respectively) than in intact controls (154.5 $\mathrm{mg}$ and $15.0 \mathrm{mg}$ (100 $\mathrm{g}$ body weight) ${ }^{-1}$; Randall, 1989b). There were significant correlations between basal values of corticotrophin (ACTH) and cortisol in fetal plasma between day 70 and day 100 $(r=0.47)$ and between days 95-100 and delivery at days 111-114 $(r=0.81)$. The slope of the regression line was significantly higher for the latter period (Silver and Fowden, 1989). The results of Randall (1989b) and Silver and Fowden (1989) indicate pituitary control of fetal adrenal growth and activity, and an increased response of the adrenal to a given concentration of ACTH in late gestation.

There is large variation among pig fetuses in the responsiveness of adrenals to ACTH after day 103 of gestation (Randall et al., 1990), and also in plasma cortisol concentrations on all days during the last weeks of gestation (Randall, 1983; Kattesh et al., 1997). It is unclear to what extent this variation in responsiveness results in variation in fetal maturation and in piglet viability and adaptability after birth. Recently, significant positive relationships have been identified between the genetic merit (estimated breeding value) of piglets for survival and their adrenal masses, as well as plasma cortisol concentrations, at day $111 \pm 1$ of gestation (J. I. Leenhouwers, unpublished) (Fig. 1).

The pituitary-thyroid system. Thyroid hormones have an important role in maintaining and regulating thermogenesis (Dauncey, 1990). Immediately after expulsion, newborn piglets are 
confronted with a temperature that is $15-20^{\circ} \mathrm{C}$ lower than the intrauterine temperature. The consequential rapid cooling of the still wet, poorly insulated piglet is often associated with a temporary decrease in body temperature and induces vigorous thermogenic responses. The pituitary-thyroid system of piglets is well matured at birth (Ślebodziński, 1988). An important role for thyroid hormones in the control of thermogenesis in this period has been suggested by Berthon et al. (1993). In their experiments, newborn piglets with induced hypothyroidism during late fetal life had a significantly larger decrease in rectal temperature and a significantly reduced maximal heat production than did control piglets. An early postnatal surge of thyroxine, total 3,5,3'-triiodothyronine and free triiodothyronine occurred in both the hypothyroid and control piglets. During the prenatal period, in the constant thermoneutral environment of the uterus, low concentrations of thyroid hormones are necessary to maintain basal fetal metabolism. During late gestation, the thyroid must grow and develop the potential for the increased demand of thyroid hormones to sustain the increase in metabolic rate for thermostability after birth. According to Liggins (1994), the conflict between low prenatal and high postnatal demand is resolved in the following two ways. Firstly, the thyroid maintains a relatively high rate of secretion of thyroxine, but deiodination of thyroxine is predominantly to the biologically inactive reverse form of triiodothyronine rather than to triiodothyronine. Secondly, the placenta maintains a high rate of metabolic clearance of triiodothyronine.

\section{Comparison of prenatal organ development in piglets with known differences in genetic} merit for piglet survival

Experimentally, it is very difficult to relate variation in prenatal organ development to perinatal survival or preweaning survival. Therefore, fetal development was investigated in relation to the genetic merit of piglets to survive from the onset of parturition to weaning. Within a large breeding population in which stillbirth, preweaning mortality and individual birth weight have been registered accurately for many years in approximately 40000 litters, the breeding values for piglet survival of all animals in the population were calculated (Knol, 2001). Knol (2001) showed that the actual difference in piglet survival between litters with a low versus a high estimated breeding value for piglet survival is almost equal to the expected difference as calculated from the breeding values. Regression coefficients of realised survival on predicted survival were close to the expected value of 1.0. A study of organ development on day $111 \pm 1$ of gestation using litters of known breeding values for piglet survival 0 . I. Leenhouwers, unpublished) revealed positive relationships of this genetic merit with proportional masses ( $\mathrm{g} \mathrm{kg}^{-1}$ body weight) of liver $(P=0.02)$, small intestine $(P=0.02)$ and stomach $(P=0.07)$. The proportional length of the small intestine $\left(\mathrm{cm} \mathrm{kg}^{-1}\right.$ body weight) was also related positively to the genetic merit for piglet survival $(P=0.08)$. The proportional masses of heart, lung, spleen and kidney were not related to genetic merit for piglet survival. Both the liver glycogen concentration ( $\mathrm{mg} \mathrm{g}^{-1}$ wet weight) and the total amount of glycogen in the liver increased with increasing genetic merit for piglet survival ( $P=0.07$ and $P=0.05$, respectively), as did the fat content of the carcasses of the fetuses $(P=0.05)$. No relationships with genetic merit for piglet survival were found for protein, ash and moisture content of the carcasses. Overall, these results indicate that piglets with a high genetic merit for survival are more mature at birth and better prepared for adaptation to extrauterine life than are piglets with a low genetic merit.

\section{Prenatal effects on glycogen reserves, glucose homeostasis and carbohydrate metabolism in the perinatal period}

As the carbohydrate metabolism of perinatal piglets is related closely to piglet viability in the perinatal period (for example see Stanton and Mueller, 1973), prenatal deposition of 
carbohydrate reserves (glycogen) and prenatal effects on perinatal glucogenic capacity, glucose homeostasis, carbohydrate metabolism and thermostability have received much attention.

\section{Prenatal glycogen deposition}

Glycogen is the main storage polysaccharide of animal cells. This polysaccharide of Dglucose in $\alpha(1,4)$ linkage is highly branched. The branches occur every $8-12$ glucose residues and the branch linkages are $\alpha(1,6)$. The glycogen reserves of piglets at the onset of parturition, for example in heart, liver and muscle, have various important roles in carbohydrate metabolism in the perinatal period. Glycogen accounts for $60-70 \%$ of the total readily available energy reserves (Mellor and Cockburn, 1986). Heart glycogen is important for resistance against anoxia during farrowing (Dawes et al., 1959; Mott, 1961; Shelley, 1961). Liver glycogen is crucial for maintaining glucose homeostasis during parturition and the immediate postpartum period, and in situations of late or low colostrum ingestion. Owing to a lack of glucose 6-phosphatase in muscles and heart, muscle and heart glycogen reserves do not have a role in glucose homeostasis. Muscle glycogen reserves primarily have a function in postnatal thermogenesis, especially in the early neonatal period before colostrum consumption and in later periods of inadequate energy intake. The absence of functional brown adipose tissue in piglets as a readily available source for early neonatal thermogenesis (Trayhurn et al., 1989) and the initial inability of neonatal piglets to use fat for this purpose indicate further the importance of glycogen reserves for postnatal thermostability.

By the end of gestation, approximately $88 \%$ of all glycogen in fetal piglets can be found in the carcass (mainly skeletal muscle), approximately $11 \%$ in the liver and the remaining $1 \%$ in heart $(0.4 \%)$, lung $(0.5 \%)$ and kidneys $(0.1 \%)$ (Okai et al., 1978). Deposition of liver glycogen starts as early as day 60 of gestation. The rate of increase of the total amount of liver glycogen (Fig. 2) is initially low but increases rapidly after day 80 of gestation and even more so after day 100 of gestation (Randall and L'Ecuyer, 1976; Okai et al., 1978; Fowden et al., 1995). Ultrastructural and stereological investigation of hepatocytes of developing fetuses have also indicated that the late prepartum period is the period of glycogen accumulation in the liver (Bielańska-Osuchowska, 1996). Deposition of glycogen in skeletal muscle may begin earlier (Randall and L'Ecuyer, 1976), and the pattern of deposition in the carcass is similar to that in the liver (Randall and L'Ecuyer, 1976; Okai et al., 1978). In several species investigated (guinea-pig, rabbit, sheep and rhesus monkey), the cardiac glycogen content ( $\mathrm{mg} \mathrm{g}^{-1}$ wet weight) reaches its highest values before the last third of gestation and decreases thereafter (Shelley, 1961). However, in pigs, the cardiac glycogen content (Fig. 2) appears to remain fairly constant throughout the second half of gestation (Randall and L'Ecuyer, 1976; Okai et al., 1978). As the mass of the heart increases during this period, the total amount of cardiac glycogen increases from only a few to $>200 \mathrm{mg}$ (Okai et al., 1978). In the lungs, glycogen concentrations are highest at about day 80 of gestation (Fig. 2) and decrease to very low concentrations at birth (Randall and L'Ecuyer, 1976; Okai et al., 1978). Glycogen in fetal lung tissue is concentrated in the fetal alveolar epithelium and the decrease in lung glycogen concentrations towards birth is associated with the loss of this epithelium (Shelley, 1961).

\section{Control of prenatal glycogen synthesis}

The enzymes involved in the synthesis of glycogen from glucose are hexokinase, phosphoglucomutase, UDP glucose pyrophosphorylase, glycogen synthetase and branching enzyme. Branching enzyme is involved in the formation of mature glycogen from the 


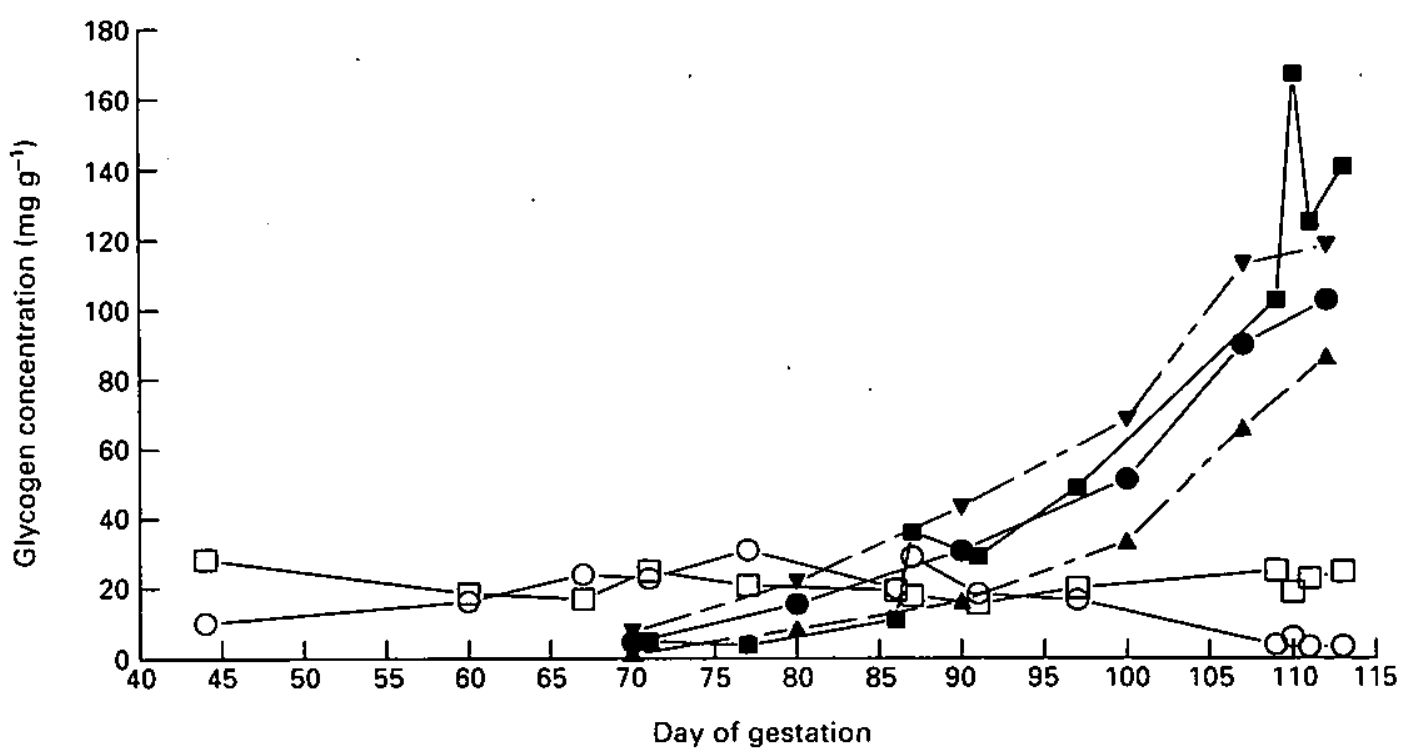

Fig. 2. Changes in liver, lung and heart glycogen concentrations in prenatal pig fetuses ( $\square$ : heart, Okai et al., 1978; O: lung, Okai et al., 1978; $\mathbf{\square}$ : liver, Okai et al., 1978; $\bullet$ : liver, Randall and L'Ecuyer, 1976; $\boldsymbol{\Delta}$ and $\nabla:$ maximum and minimum liver glycogen concentrations, respectively Randall and L'Ecuyer, 1976).

glycogen $\alpha(1,4)$ polymer. The rate-limiting enzyme in glycogen synthesis is glycogen synthetase. There are two forms of glycogen synthetase: the ' $a$ ' form (active form) and the ' $b$ ' form (inactive form) (Hers et al., 1969). The interconversion of these two forms is achieved by phosphorylation (inactivation) and dephosphorylation (activation) and can be influenced by glucocorticosteroids (De Wulf et al., 1968).

Our current knowledge about the control of glycogen deposition in fetal pigs is incomplete. The large increase in liver glycogen deposition during the last weeks of gestation coincides with the prepartum increase in circulating fetal glucocorticosteroid concentrations. Evidence that cortisol is involved in glycogen deposition comes from experiments in which cortisol was infused into intact (Fowden et al., 1985, 1995) or hypophysectomized (Randall, 1987, 1988) pig fetuses. Fowden et al. (1985) showed that hepatic glycogen deposition could be stimulated by cortisol well before the normal increase in prepartum deposition. Furthermore, it has been shown that 6 days of s.c. cortisol infusion into fetal pigs, starting at days 82-84 or 92-94 of gestation, significantly increases the already ongoing hepatic glycogen deposition (Fowden et al., 1995). Although the experiment of Randall (1988) with chronically catheterized hypophysectomized fetal pigs confirmed that cortisol is an important stimulant for liver glycogen deposition, other hormones may be necessary for maximal response, especially in muscle glycogen deposition. For example, insulin may be involved. Chronic hyperinsulinaemia in euglycaemic pig fetuses increases both liver and muscle glycogen concentrations (Garssen et al., 1983).

Knowledge about the regulation of glycogen synthesis in other species confirms the role of glucocorticosteroids in liver glycogen synthesis (Liggins, 1994) and also indicates other hormones that may be involved. Hepatic glycogen deposition in sheep is stimulated by endogenous placental lactogen (Schoknecht et al., 1996) and is mediated through binding to specific placental lactogen receptors (Freemark and Handwerger, 1986). A role for placental lactogens in pigs is not likely, as at present there is no evidence for the production of 
lactogenic factors by pig placenta. Studies in other species have also indicated the involvement of growth factors in prenatal glycogen deposition. In a study with insulin-like growth factor II (IGF-II)-deficient mice, Lopez et al. (1999) showed that IGF-II is involved in the regulation of glycogen synthesis. These authors suggested that IGF-II might operate through stimulation of glycogen synthetase activity. The role of IGF-II on glycogen deposition in fetal pigs has, to our knowledge, not been investigated, but indirect evidence indicates that its role may be either small or facilitating. The IGF-II concentration in fetal pigs is relatively low ( $\pm 125 \mathrm{ng} \mathrm{ml}^{-1}$ ) and increases after birth (Peng et al., 1996). Hypophysectomy of fetal pigs did not appear to affect serum and tissue IGF-II concentrations (Latimer et al., 1993), but decreased the amount of glycogen in liver (from $7.2 \pm 0.6$ to $2.0 \pm 0.5 \%$ wet weight) and skeletal muscle (from $6.1 \pm 0.3$ to $3.0 \pm 0.5 \%$ wet weight) at days 103-108 of gestation (Randall, 1988). Infusion of cortisol in these hypophysectomized fetuses between day 100 and day 104 of gestation increased the liver and skeletal muscle glycogen concentrations $(+112 \%$ and $+44 \%$, respectively). However, these concentrations were still below the concentrations in intact fetuses (Randall, 1988). These results indicate at most a limited role for IGF-II in glycogen synthesis in pig fetuses, but the possibility that the presence of IGF-II may be necessary for the effect of cortisol cannot be ruled out.

\section{Manipulating prenatal glycogen deposition}

Glycogen reserves of piglets at birth can be influenced by restricting the feed intake of sows during late gestation (Elliot and Lodge, 1977; Ojamaa et al., 1980) or by feeding sows additional energy during late gestation (Seerley et al., 1974; Coffey et al., 1982; Seerley, 1989). Elliot and Lodge (1977) and Ojamaa et al. (1980) restricted the feed intake of sows and gilts from day 100 and day 87 of gestation, respectively, and observed negative effects on liver glycogen concentrations $(-19.3 \%$ and $-7.9 \%$, respectively) relative to controls. Muscle glycogen concentration was hardly affected in the study of Elliot and Lodge (1977) but was slightly decreased ( $-6 \%$ relative to controls) in the study of Ojamaa et al. (1980). Both studies were performed with relatively low numbers of experimental animals and no information on piglet survival was reported in either study. Seerley et al. (1974) fed sows additional cornstarch or corn oil from day 109 of gestation and found higher glycogen concentrations ( $\mathrm{mg} \mathrm{g}^{-1}$ wet tissue) in liver (on average $+12 \%$ ) and longissimus muscle (on average $+16 \%$ ) in both groups compared with the control group. All increases were significant except that of the liver glycogen content in the group fed additional corn oil. Nevertheless, this increase was comparable to that in the group fed with cornstarch. In the study of Seerley (1989), piglets of sows fed additional fat from day 80 (5\% added solid fat pellets) or day $100(10 \%$ added solid fat pellets) of gestation were compared with those of sows fed the same diet without additional fat. In both experimental groups, the liver glycogen concentration increased significantly by $16 \%$ and the total amount of liver glycogen increased by $41 \%$. These results are in agreement with the results of Coffey et al. (1982), who found $11-23 \%$ higher piglet liver glycogen concentrations in sows fed additional animal fat compared with sows fed additional cornstarch. In the studies of Seerley et al. (1974) and Seerley (1989), the increased glycogen reserves in the experimental groups had only a small positive effect on piglet survival. In the corn oil group of the study by Seerley et al. (1974), a significantly higher percentage of piglets weighing $<1.0 \mathrm{~kg}$ at birth survived to day 21 compared with the control group. In an experiment by Boyd et al. $(1978 a, b)$ in which gilts were fed additional tallow or cornstarch from day 100 of gestation, no significant effects on fetal liver glycogen were found relative to the control group (Boyd et al., 1978a), but survival until day 14 after parturition among piglets weighing $<1.0 \mathrm{~kg}$ at birth was also increased significantly (mortality rates: tallow group: 
46.3\%; cornstarch group: $57.1 \%$; control group: $72.5 \%$; Boyd et al., 1978b). Effects of sow nutrition in late gestation on the survival of piglets weighing $<1.0 \mathrm{~kg}$ have also been found by Okai et al. (1977), but these authors did not report data on piglet liver glycogen content.

\section{Prenatal effects on glucose concentrations in the perinatal period}

Blood glucose concentrations in fetal pigs remain relatively constant until the end of gestation and increase rapidly during or after expulsion of the piglet (Randall, 1982). This increase is almost certainly a result of increased secretion of catecholamines (adrenaline and noradrenaline). Injections of adrenaline or noradrenaline in newborn piglets increased plasma glucose concentrations in a dose-dependent manner, although adrenaline had a larger effect than noradrenaline (Stanton and Mueller, 1973). The timing of the rapid increase in blood glucose concentration is related to the course of expulsion. In normal deliveries, the increase occurs as late as several minutes after expulsion. In deliveries associated with asphyxiation, a rapid increase is observed during expulsion. Herpin et al. (1996) showed a curvilinear relationship between the glucose concentration of the piglet immediately after expulsion and the extent of asphyxia during delivery. The earlier increase in glucose concentrations in asphyxiated piglets may prevent or at least reduce the pathophysiological effects of hypoxia on the brain (McGowan et al., 1995).

In addition to the progress of farrowing, perinatal blood glucose concentrations in piglets are also affected by the glucose tolerance of the sow during late gestation. Variation in glucose tolerance of apparently normal sows was recognized as early as the late nineteenth century (see Bunding et al., 1956). As in many other mammalian species, the glucose tolerance in sows is affected adversely by gestation and results in a diabetogenic state of the dam (George et al., 1978; Bouillon-Hausman et al., 1986; Schaefer et al., 1988; Schaefer et al., 1991; Kemp et al., 1996; Père et al., 2000). The available data show that the diabetogenic state of sows increases with the stage of gestation (George et al., 1978; Père et al., 2000) and indicate that, for a given day of gestation, the glucose tolerance varies largely among individual sows (George et al., 1978; Kemp et al., 1996). Fetuses developing in diabetogenic sows with mild hyperglycaemia are both hyperglycaemic and hyperinsulinaemic. As soon as the piglet is expelled and maternal glucose is no longer maintaining high glucose concentrations in the blood of the piglet, the high piglet insulin concentrations are maintained by its hyperplasic pancreatic islets of Langerhans. Although the piglets are born hyperglycaemic, they soon become hypoglycaemic for some time (Phillips et al., 1980). This transient hypoglycaemia leads to reduced vigour, suboptimal colostrum intake and chilling, thereby increasing the risk of mortality. Under normal practical conditions in a well-managed pig unit, Kemp et al. (1996) found a significant increase in piglet mortality rate until day 7 after farrowing with an increase in the preparturient diabetogenic state of the dam. As piglets from diabetogenic sows have larger glycogen reserves (Ezekwe et al., 1984), they may have a better ability to withstand long-term adverse conditions after they have survived the short-term hypoglycaemia. In agreement with this, Kasser et al. (1982) found that newborn piglets of alloxan-induced diabetogenic sows had a better ability to survive long-term $(>36 \mathrm{~h})$ fasting at $32^{\circ} \mathrm{C}$ than did piglets from control (non-alloxan-treated) sows kept at the same temperature. Thus, the overall effect of the degree of glucose tolerance of the sow during late gestation on the perinatal survival rate will probably depend on the nutritional state of the piglets and on the ambient temperature.

To our knowledge, it is still unknown whether fetal hyperglycaemia in late gestation of pigs may affect specific fetal maturational processes and, thus, influence early neonatal viability. Work in other species indicates negative effects of fetal hyperglycaemia during the later stages 
of gestation on lung maturation. For example, in sheep, chronic hyperglycaemia with secondary hyperinsulinaemia inhibits the maturational response of fetal lungs to cortisol (Warburton, 1983). In streptozotocin-diabetic rats, the ensuing fetal hyperglycaemia, in the absence of hyperinsulinaemia, was also associated with delayed lung maturation. The lungs showed a decrease in surfactant phospholipid synthesis, decreased surfactant apoprotein and a decrease in the activity and mRNA of $\mathrm{Na}^{+}, \mathrm{K}^{+}$-ATPase (Warshaw, 1990). On the basis of the knowledge currently available (for example see Bourbon and Farrell, 1985), it can be concluded that hyperglycaemia has direct effects on lung maturation (for example see Warshaw, 1990), as well as indirect effects through secondary hyperinsulinaemia (for example see Engle et al., 1983; Biasini et al., 1994).

\section{References}

Berthon D, Herpin P, Duchamp C, Dauncey MJ and Le Dividich J (1993) Modification of thermogenic capacity in neonatal pigs by changes in thyroid status during late gestation Journal of Developmental Physiology 19 253-261

Biasini A, Casadei G and Cerasoli C (1994) II figlio di madre diabetica Minerva Endocrinologica 19 91-94

Bielańska-Osuchowska Z (1996) Ultrastructural and stereological studies of hepatocytes in prenatal development oi swine Folia Morphologica (Warsz.) 55 1-19

Björklund N-E, Svendsen J and Svendsen LS (1987) Histomorphological studies of the perinatal pig: comparison of five mortality groups with unaffected pigs Acta Veterinaria Scandinavica 28 105-116

Bouillon-Hausman D, Kasser TR, Seerley RW and Martin RJ (1986) Sludies of gestational diabetes using the pig as a model. In Sivine in Biomedical Research Volume 1 pp 561-572 Ed. ME Tumbleson. Plenum Press, New York

Bourbon JR and Farrell PM (1985) Fetal lung development in the diabetic pregnancy Pediatric Research 19 253-267

Boyd RD, Moser BD, Peo ER and Cunningham PJ (1978a) Effect of energy source prior to parturition and during laclation on tissue lipid, liver glycogen and plasma levels of some metabolites in the netwborn pig fournal of Animal Science 47 874-882

Boyd RD, Moser BD, Peo ER and Cunningham PJ (1978b) Effect of energy source prior to parturition and during lactation on piglet survival and growth and on milk lipids Journal of Animal Science 47 883-892

Buddington RK and Malo C (1996) Intestinal brush-border membrane enzyme activities and transport functions during prenalal development oi pigs journal of Pediatric Gastroenterology and Nutrition 23 51-64

Bunding IM, Davenport ME and Schooley MA (1956) The glucose tolerance test in swine and its implications journal of Animal Science 15 234-241

Chiang FE and Rodway RG (1997) Determinations of umbitical cord $\beta$-endorphin concentration and blood gas parameters in newborn piglets Research in Veterinary Science 63 107-111

Coffey MT, Seerley RW, Martin RJ and Mabry IW (1982) Effect of level, source and duration of íeeding of supplemental energy in sow diets on metabolic and hormonal traits related to energy utilization in the baby pig fournal of Animal Science 55 329-336

Dauncey MJ (1990) Thyroid hormones and thermogenesis Proceedings of the Nutrition Society 49 203-215

David J-C and Grongnet J-F (2000) Effect of hypoxia on DNA fragmentation in different brain regions of the newborn piglet Molecular Reproduction and Development 57 153-158

Dawes GS, Mott JC and Shelley HJ (1959) The importance of cardiac glycogen for the maintenance of life in foetal lambs and new-born animals during anoxia journal of Physiology 146 516-538

Dawes CS, Jacobson HN, Mott JC, Shelley $H$ J and Stafiord A (1963) The treatment of asphyxiated, mature, foetal lambs and rhesus monkeys with intravenous glucose and sodium carbonate fournal of Physiology, London 169 167-184

De Wulf H, Stalmans W and Hers HG (1968) The influence of inorganic phosphate, adenosine triphosphate and glucose 6-phosphate on the aclivity of liver glycogen synthetase European fournal of Biochemistry 6 545-551

Elliot JI and Lodge CA (1977) Body composition and glycogen reserves in the nconatal pig during the first 96 hours postpartum Canadian Journal of Animal Science 57 141-150

Engle MJ, Langan SM and Sanders RL (1983) The effects of insulin and hyperglycaemia on surfactant phospholipid sunthesis in organotypic cultures of type II pneumocytes Biochimica et Biophysica Acta 753 6-13

English PR and Morrison V (1984) Causes and prevention of piglet mortality Pig News and information 5 369-376

English PR and Smith WJ (1975) Some causes of death in neonatal piglets The Veterinary Annual 15 95-104

Ezekwe MO, Ezekwe EI, Sen DK and Ogolla F (1984) Effects of maternal streptozotocin-diabetes on fetal growth, energy reserves and body composition of newborn pigs Journal of Animal Science 59 974-980

Fowden AL, Comline RS and Silver M (1985) The eífects of cortisol on the concentration of glycogen in difíerent tissues in the chronically catheterized fetal pig Quarterly Journal of Experimental Physiology 70 23-35

Fowden AL, Apatu RSK and Silver M (1995) The glucogenic capacity of the fetal pig: devclopmental regulation by cortisol Experimental Physiology 80 457-467 
Fraser D, Phillips PA, Thompson BK, Pajor EA, Weary DM and Braithwaite LA (1995) Behavioural aspects of piglet survival and growth. In The Neonatal Pig: Development and Survival pp 287-312 Ed. MA Varley. CAB International, Wallingford

Freemark $M$ and Handwerger S (1986) The glycogenic effects of placental lactogen and growth hormone in ovine fetal liver are mediated through binding to specific fetal ovine placental lactogen receptors Endocrinology $118613-618$

Garssen GJ, Spencer GSG, Colenbrander B, Macdonald AA and Hill DJ (1983) L.ack of effect of chronic hyperinsulinaemia on growth and body composition in the fetal pig Biology of the Neonate 44 234-242

George PB, England DC, Siers DC and Stanton HC (1978) Diabetogenic effects of pregnancy in sows on plasma glucose and insulin release journal of Animal Science 46 1694-1700

Glastonbury JRW (1977) Preweaning mortality in the pig. Pathological findings in piglets dying before and during parturition Australian Veterinary Journal 53 282-286

Gross I (1990) Regulation of felal lung maturation American journal of Physiology 259 L337-L344

Herpin P, Le Dividich ], Hulin JC, fillaut M, De Marco F and Bertin R (1996) Eiffects of the level of asphyxia during delivery on viability at birth and early postnatal vitality of newborn pigs Journal of Animal Science 74 2067-2075

Herpin P, Wosiak F, Le Dividich J and Bertin R (1999) Effects of acute asphyxia at birth on subsequent heat production capacily in newborn pigs Research in Veterinary Science $6645-49$

Hers HG, De Wulf H, Stalmans W and Van den Berghe $G$ (1969) The control of glycogen synthesis in the liver Advances in Enzyme Regulation 8 171-190

Hillyer GM and Phillips P (1980) The effect of increasing feed level to sows and gilts in late pregnancy on subsequent litter size, litter weight and maternal bodyweight change Animal Production 30469 (Abstract)

Hsu P, Hafíner I, Albuquerque MLC and Leffler CW (1996) $\mathrm{pH}_{\mathbf{i}}$ in piglet cerebral microvascular endothelial cells: recovery from an acid load Proceedings of the Society for Experimental Biology and Medicine 212 256-262

Hume R, Conner C and Gilmour M (1996) Lung maturation Proceedings of the Nutrition Society 55 529-542

Kasser TR, Gahagan JH and Martin RJ (1982) Fetal hormones and neonatal survival in response to altered maternal serum glucose and free fatty acid concentrations in pigs Journal of Animal Science 55 1351-1359

Kattesh HG, Baumbach GA, Gillespie BB, Schneider JF and Murai JT (1997) Distribution between protein-bound and free forms of plasma cortisol in the gilt and fetal pig near term Biology of the Neonate 72 192-200

Kemp B, Soede NM, Vesseur PC, Helmond FA, Spoorenberg JH and Frankena K (1996) Glucose tolerance of pregnant sows is related to postnatal pig mortality fournal of Animal Science 74 879-885

Kerr IC and Cameron ND (1995) Reproductive performance of pigs selected for components of efficient lean growth Animal Science 60 281-290

Knol EF (2001) Genetic Aspects of Piglet Survival PhD thesis, Wageningen University
Latimer AM, Hausman GJ, McCusker RH and Buonomo FC (1993) The effects of thyroxine on serum and tissue concentrations of insulin-like growth factors (IGF-I and -II) and IGF-binding proteins in the fetal pig Endocrinology 133 1312-1319

Ledwozyw A (1989) Changes in the content of lung surfactant phospholipid and fatty acid in pigs during ontogenesis and in a nearly post-natal period Medycyna Weterynaryjna 45 369-374

Lee GJ and Haley CS (1995) Comparative farrowing to iveaning performance in Meishan and Large White pigs and their crosses Animal Science 60 269-280

Leenhouwers II, van der Lende T and Knol EF (1999) Analysis of stillbirth in different lines of pig Livestock Production Science 57 243-253

Liggins CC (1994) The role of cortisol in preparing the fetus for birth Reproduction, Fertility and Development 6 $141-150$

Lopez MF, Dikkes $P$, Zurakowski D, Villa-Komaroff $L$ and Majzoub JA (1999) Regulation of hepatic glycogen in the insulin-like growth factor II-deficient mouse Endocrinology $1401442-1448$

McGowan JE, Marro PJ, Mishra OP and DelivoriaPapadopoulos M (1995) Brain cell membrane function during hypoxia in hyperglycemic newborn piglets Pediatric Research 37 133-139

Martin RJ, Hausman GJ and Hausman DB (1998) Regulation of adipose cell development in utero. Proceedings of the Society for Experimental Biology and Medicine 219 200-210

Mellor DJ and Cockburn F (1986) A comparison of energy metabolism in the newborn infant, piglet and lamb Quarterly lournal of Experimental Physiology 71 361-379

Mersmann HJ, Pond WG, Stone RT, Yen IT and Lindvall RN (1984) Factors affecting growth and survival of neonatal genetically obese and lean sivine: cross fostering experiments Growth 84 209-220

Miller HM, Foxcroft GR and Aherne FX (2000) Increasing food intake in late gestation improved sow condition throughout lactation but did not affect piglet viability or growth rate Animal Science 71 141-148

Miller JA and Miller FS (1965) Studies on prevention of brain damage in asphyxia Developmental Medicine and Child Neurology 7 607-619

Moss IR and Scarpelli EM (1981) $\beta$-Endorphin: central depression of respiration and circulation fournal of Applied Physiology $501011-1016$

Mott IC (1961) The ability of young mammals to withstand total oxygen lack British Medical Bulletin 17 144-148

Muglia L, Jacobson L, Dikkes P and Majzoub JA (1995) Corticotropin-releasing hormone deficiency reveals major fetal but not adult glucocorticoid need Nature $373427-432$

Murphy SI, Song D, Welsh FA, Wilson DF and Pastuzko A (1996) The effect of hypoxia and catecholamines on regional expression of heat-shock protein-72 mRNA in neonatal piglet brain Brain Research 727 145-152

Ojamaa KM, Elliot Jl and Hartsock TG (1980) Effecls of gestation feeding level on glycogen reserves and blood parameters in the newborn pig fournal of Animal Science 51 620-628 
Okai DB, Aherne FX and Mardin RT (1977) Effects of sow nutrition in late gestation on the body composition and survival of the neonatal pig Canadian fournal of Animal Science 57 439-448

Okai DB, Wyllie D, Aherne FX and Ewan RC (1978) Glycogen reserves in the fetal and newborn pig Journal of Animal Science 46 391-401

Peng $M$, Pelletier $G$, Palin M-F, Véronneau S, LeBel D and Abribat T (1996) Ontogeny of IGFs and IGFBPS mRNA levels and tissue concentrations in liver, kidney and skeletal muscle oi pig Growth, Development and Aging 60171-187

Père MC, Etienne M and Dourmad JY (2000) Adaptations of glucose metabolism in multiparous sows: effects of pregnancy and feeding level fournal of Animal Science 78 2933-2941

Phillips RW, Panepinto LM, Will DH and Case GL (1980) The effects of alloxan diabetes on Yucatan miniature swine and their progeny Metabolism $2940-45$

Pond WG and Mersmann HJ (1995) Genetically diverse pig models in nutrition research related to lipoprotein and cholesterol metabolism. In International Symposia of Swine in Biomedical Research pp 843-864 Eds $M$ Tumbelson and I. Schook. Plenum Press, New York

Pond WG, Yen IT, Maurer RR and Christenson RK (1981) Effect of doubling daily energy intake during the last two weeks of pregnancy on pig birth weight, survival and weaning weight journal of Animal Science 52 535-541

Randall GCB (1972a) Observations on parturition in the sow. I. Factors associated with the delivery of the piglets and their subsequent behaviour Veterinary Record $\mathbf{9 0}$ 178-182

Randall GCB (1972b) Observations on parturition in the sow. II. Factors iniluencing stillbirth and perinatal mortality Veterinary Record 90 183-186

Randall GCB (1982) Changes in fetal and maternal blood at the end of pregnancy and during parturition in the pig Research in Veterinary Science 32 278-282

Randall GCB (1983) Changes in the concentrations of corticosteroids in the blood of fetal pigs and their dams during late gestation and labor Biology of Reproduction $291077-1084$

Randall GCB (1987) Effect of hypophysectomy on tissue glycogen concentrations in the fetal pig Biology of the Neonate 52 174-180

Randall GCB (1988) Tissue glycogen concentrations in hypophysectomized pig fetuses following infusion with cortisol Journal of Developmental Physiology 10 77-83

Randall GCB (1989a) form and development of the umbilical cord in pigs and their association with delivery of viable pigs American fournal of Veterinary Research 50 1512-1515

Randall GCB (1989b) Effect of hypophysectomy on body and organ weights and subsequent development in the fetal pig Canadian Journal of Animal Science 69 655-661

Randall GCB and L'Ecuyer C (1976) Tissue glycogen and blood glucose and fructose levels in the pig fetus during the second half of gestation Biology of the Neonate $\mathbf{2 8}$ 74-82

Randall GCB, Kendall JZ, Tsang BK and Taverne MAM
(1990) Endocrine changes following infusion of fetal pigs with corticotropin in litters of reduced numbers Animal Reproduction Science 23 109-122

Roehe R (1999) Genetic determination of individual birth weight and its association with sow productivity traits using Bayesian analyses Journal of Animal Science 77 330-343

Roehe R and Kalm E (2000) Estimation of genetic and environmental risk factors associated with pre-weaning montality in piglets using generalized linear mixed models Animal Science 70 227-240

Sangild PT (1995) Stimulation of gastric proteases in the neonatal pig by a rise in adrenocortical secretion at parturition Reproduction, Fertility and Development 7 1293-1298

Sangild PT, foltmann $B$ and Cranwell PD (1991) Development of gastric proteases in f́etal pigs and pigs from birth to thirty-six days of age. The effect of adrenocorticotropin (ACTH) Journal of Developmental Physiology 16 229-238

Sangild PT, Sjöström H, Norén O, Fowden AL and Silver M (1995) The prenatal development and glucocorticoid control of brush-border hydrolases in the pig small intestine Pediatric Research 37 207-212

Sangild PT, Fowden AL and Trahair IF (2000) How does the foetal gastrointestinal tract develop in preparation for enteral nutrition after birth? Livestock Production Science 66 141-150

Schaefer AL, Jones SDM, Newman JA, Sather AP and Tong AKW (1988) Reproductive performance, fetal growth, carcass composition and glucose tolerance in pregnant gilts given a dietary protein supplement Canadian journal of Animal Science 68 677-687

Schaefer AL, Tong AKW, Sather AP, Beltranena E, Pharazyn $A$ and Aherne FX (1991) Preparturient diabetogenesis in primiparous gilts Canadian journal of Animal Science 71 69-77

Schoknecht PA, Ebner S, Pond WG et al. (1994) Dietary cholesterol supplementation improves growth and behavioural response of pigs selected for genetically high and low serum cholesterol fournal of Nutrition 124 305-314

Schoknecht PA, McGuire MA, Cohick WS, Currie WB and Bell AW (1996) Effect of chronic infusion of placental lactogen on ovine fetal growth in late gestation Domestic Animal Endocrinology 13 519-528

Seerley RW (1989) Survival and postweaning performance of pigs from sows fed fat during late gestation and lactation Journal of Animal Science 67 1889-1894

Seerley RW, Pace TA, Foley CW and Scarth RD (1974) Efíect of energy intake prior to parturition on milk lipids and survival rate, thermostability and carcass composition of piglets fournal of Animal Science 38 64-70

Shelley HJ (1961) Glycogen reserves and their changes at birth and in anoxia British Medical Bulletin 17 137-143

Silver $M$ and fowden AL (1989) Pituitary adrenocortical activity in the fetal pig in the last third of gestation Quarterly Journal of Experimental Physiology 74 197-206

Ślebodziński AB (1988) Hyperiodothyroninaemia of 
neonates, its significance for thermogenesis Acta Physiologica Poland 39 364-379

Sprecher DJ, Leman AD, Dziuk PD, Cropper $M$ and DeDecker $M$ (1974) Causes and control of swine stillbirths Journat of the American Veterinary Medical Association 165 698-701

Stanton HC and Carroll JK (1974) Potential mechanisms responsible for prenatal and perinatal mortality or low viability of swine fournal of Animal Science 38 1037-1044

Stanton HC and Mueller RL (1973) Metabolic responses to cold and catecholamines as a function of age in swine (Sus domesticus). Comparative and Biochemical Physiology 45A 215-225

Sterling LG and Cline TR (1986) The effect of energy level in - late gestation and lactation on the sow and litter: growth and reproductive performance Journal of Animal Science 63 (Supplement 1) 115 (Abstract)

Svendsen J (1992) Perinatal mortality in pigs Animal Reproduction Science 28 59-67

Svendsen LS (1982) Organ weights of the newborn pig. Characterization and comparison of the organ weights of pigs dying within 48 hours of birth with those of unaffected, growing pigs: stillborn intra partum pigs, weak pigs, splayleg pigs, splayleg and weak (splayweak) pigs, and traumatized pigs Acta Veterinaria Scandinavica Supplementum $781-205$

Svendsen LS, Weström BR, Svendsen I, Olsson A-Ch and Karlsson BW (1990) Intestinal macromolecular transmission in underprivileged and unaffected newborn pigs: implication for survival of underprivileged pigs Research in Veterinary Science 48 184-189

Taverne MAM, Naaktgeboren $C$ and Van der Weyden GC (1979) Myometrial activity and expulsion of fetuses Animal Reproduction Science 2 117-131

Thornbury IC, Sibbons PD, Van Velzen D, Trickey $R$ and Spitz L (1993) Histological investigations into the relationship between low birth weight and spontaneous bowel damage in the neonatal piglet Pediatric Pathology 13 59-69

Torday IS, Sun H and Qin J (1998) Prostaglandin $E_{2}$ integrates the effects of fluid distension and glucocorticoid on lung maturation American fournal of Physiology 274 L.106-1.111

Trayhurn P, Temple NJ and Van Aerde J (1989) Evidence from immunoblotting studies on uncoupling protein that brown adipose tissue is not present in the domestic pig Canadian Journal of Physiology and Pharmacology 67 1480-1485

Tuchscherer M, Puppe B, Tuchschere $A$ and Tiemann $U$ (2000) Early identification of neonates at risk: traits of newborn piglets with respect to survival Theriogenology $54371-388$

van der Lende $T$ and De Jager $D$ (1991) Death risk and preweaning growth rate of piglets in relation to the within-litter weight distribution at birth Livestock Production Science 28 73-84

Waldorf DP, Foote WC, Self HL, Chapman AB and Casida LE (1975) Factors affecting fetal pig weight late in gestation Journal of Animal Science 16 976-985

Warburton D (1983) Chronic hyperglycemia with secondary hyperinsulinemia inhibits the maturational response of fetal lamb lungs to cortisol fournal of Clinical Investigation 72 433-440

Warshaw JB (1990) Nutritional correlates of fetal growth Developmental Pharmacology and Therapeutics 15 153-158

Wise T, Roberts A) and Christenson RK (1997) Relationship of light and heavy fetuses to uterine position, placental weight, gestational age, and fetal cholesterol concentrations Journal of Animal Science 75 2197-2207

Zaleski HM and Hacker RR (1993) Variables related to the progress of parturition and probability of stillbirth in swine Canadian Veterinary Journal 34 109-113 